Thorax (1954), 9, 154.

\title{
HONEYCOMB LUNG AND MITRAL STENOSIS IN SCLERODERMA
}

\author{
BY \\ M. EVANS AND R. A. PARKER \\ From the Departments of Medicine and Pathology, Welsh National School of Medicine, Cardiff
}

(RECEIVED FOR PUBLICATION NOVEMBER 16, 1953)

Patients with scleroderma (acrosclerotic type) have been found fairly frequently to have pulmonary fibrosis, and rarely a cystic appearance of the lung evident radiologically and at necropsy. Hayman and Hunt (1952) found and reviewed 27 cases from the literature with fibrosis, of which six had cysts (Getzowa, 1945 ; Dostrovsky, 1947 ; Spain and Thomas, 1950 ; Church and Ellis, 1950), and they added a seventh of their own with cyst formation. Aronson and Wallerstein (1950) have also described a case, making eight in all, four of which have been confirmed at necropsy.

Clinical association of scleroderma and mitral stenosis has been recorded by Crocker (1885), Ramond (1928), and Ramsey (1951), in a total of four cases. The account by Rake (1931) is the only one we can find in which the diagnosis was confirmed post mortem.

In this paper we present the clinical course and necropsy findings in a patient with two rare lesions in association with scleroderma, namely, cystic changes in the lungs and mitral stenosis.

\section{Case Report}

A housewife, aged 51, gravely ill and in severe pain, was admitted to the Medical Unit, Royal Infirmary, Cardiff, on January 10, 1952. There was a vague history of rheumatic pain when 8 years old, but no history of rheumatic fever. During her school days she had been subject to Raynaud's phenomenon and chilblains on the extremities. These symptoms recurred, together with pain in the feet, 10 years before admission. Ulcerations of the skin followed, first on the legs, and later also on the feet, toes, and fingers. For about eight years she had noticed progressive stiffness of fingers, wrists, ankles, and knees, pain and slight swelling in the arms and legs after exercise, and progressive hardness and stiffness of the skin of the hands and feet, with deformity and destruction of the terminal phalanges. She complained of breathlessness and palpitation on exertion, and had a frequent cough.

She was admitted on several occasions to another hospital between 1946 and 1949, and had, at intervals, right lumbar, right and left cervico-dorsal, and left lumbar sympathectomies, respectively. Respiratory $\vec{J}$ complications followed the first operation; there were signs of consolidation, initially over both lung bases, and later over the right middle lobe, and after the second operation she was febrile for a week.

During the six months before admission her general $\underset{\sigma}{\sigma}$ condition deteriorated rapidly. She had anorexia, $\vec{\theta}$ severe general malaise, marked loss of weight, retro- $f$ sternal burning pain after meals, gangrene of some ${ }^{\ddagger}$ fingers and toe tips, and painful superficial ulcers on $\square$ the ears.

On examination she was emaciated, pale, orthopnoeic, and had a frequent productive cough. There was patchy brown pigmentation of the skin all over $\frac{\circ}{\mathbb{Q}}$ the body, most marked over the legs and forearms, and $\varrho$ slight bilateral ptosis. The skin of the face was thin, $\overrightarrow{0}$ pigmented, and tightly stretched over the bony struc- 3 tures. Thin, slightly retracted lips showed furrowing. She had stiff, claw-like hands with scarred, shortened and blunt terminal phalanges, deformed nails, and a number of scars and shallow ulcers on the fingers. The skin over the fingers and thumbs was hard, $\frac{O}{0}$ smooth, and fixed; that over the rest of the hands $x$ was tightly stretched, hard, and inflexible, but not $\frac{9}{3}$ immovable. There was a gradual transition to normal skin in the forearm. Similar changes, but to a more $O$ severe degree, were present on the feet and extended $₹$ up to the middle of the legs, with a number of shallow 을 ulcers over the feet and legs and pigmented scarring $>$ of the skin between them. The skin of the neck and o upper part of the chest was thin and taut. Elsewhere it was normal, but despite extreme emaciation was $N$ tightly applied to the body. Patches of atrophied $N$ skin with telangiectasis were present over the face, $\mathcal{N}$ neck, manubrium, and forearms. Movements of the $\omega$ fingers, toes, and hands were severely restricted by the sclerotic skin. There was periarticular thickening 0 and tenderness of the elbow-, ankle-, and knee-joints, $\underset{\mathbb{D}}{\mathbb{2}}$ with limitation of movement, particularly in the knee- $\stackrel{\mathcal{P}}{+}$ joints. There was marked wasting and tenderness of 0 muscles generally. Small glands were palpable in the axillae and groins.

There was sacral oedema, but none elsewhere; $\frac{\rho}{\mathbb{Q}}$ slight cyanosis and pallor, with cold extremities; no $\stackrel{\mathbb{Q}}{\varrho}$ rise of jugular venous pressure. The blood pressure was $140 / 80(\mathrm{~mm} . \mathrm{Hg})$. There was auricular fibrilla- 0 tion (ventricular rate about 100 per minute). The apex beat was easily palpable $4 \frac{3}{4}$ in. $(12 \mathrm{~cm}$.) from the 
mid-sternal line in the fifth space. A systolic thrill was easily palpable over the mitral area. There was a slapping first mitral and loud second pulmonary sound, a widely propagated harsh systolic apical murmur and, on one occasion only, a diastolic mitral murmur. The chest was deformed due to scoliosis, and expansion was restricted. The lungs were resonant all over, and persistent inspiratory crepitations were audible over both lung bases up to the angles of the scapulae. Movements of the left side of the soft palate were very limited, and this area was indurated. Apart from ptosis, and marked muscle wasting and weakness, no significant abnormality was detected in the nervous system.

Albumin, hyaline, and granular casts were persistently present in the urine. She had a hypochromic anaemia, and a polymorphonuclear leucocytosis of 11,400 per c.mm., and the E.S.R. was raised to $54 \mathrm{~mm}$. after one hour. The blood urea was $24 \mathrm{mg}$. per $100 \mathrm{ml}$.; total serum proteins $7.0 \mathrm{~g}$. per $100 \mathrm{ml}$. (albumin 3.8 and globulin $3.2 \mathrm{~g}$. per $100 \mathrm{ml}$.). Kahn and Wassermann reactions were negative. Sputum was persistently negative for tubercle bacilli. Electrocardiograms showed intermittent auricular fibrillation, a high-voltage $R$ wave in $V_{4}$ and $V_{5}$, and occasional ventricular extrasystoles.

A series of chest radiographs taken in the last four years showed a depression of the horizontal fissure, slight cardiac shift to the right, elevation of the right diaphragm, and prominent crowded lung markings in the right cardiophrenic angle. Linear shadowing with a cystic pattern, initially present in both lower zones and at the outer thirds of the lung fields, became more widely distributed, although always more pronounced on the right side. In addition (Fig. 1), the right lung was finely mottled with small opacities variable in size and shape.

The cardiac outline remains unchanged in the series and is typical of mitral stenosis, with moderate enlargement of the left atrium.

Examination of the oesophagus by barium swallow on February 6, 1952, showed it to be uniformly dilated, peristalsis was absent, and the only movement noted was slight in amount and non-propulsive. There was no evidence of ulceration or of hiatus hernia, and no reflux at the cardia was produced by tilting. The oesophagus partially emptied when the barium accumulated to a height of 5 or 6 in. The column was prominently indented by the left atrium.

Radiographs of the hand showed varying degrees of absorption of the terminal phalanges, and flexion deformities of all finger and thumb joints. No calcification in the soft tissues was noted in any of the parts radiographed.

Progress.-Throughout the period of observation (10 weeks) the patient was in a very grievous state with continuous pain from the skin ulcers. She had an irregular pyrexia, persistent polymorphonuclear leucocytosis, an elevated E.S.R., and progressive anaemia. Breathlessness and productive cough were present from time to time, and also a varying degree of congestive cardiac failure. In the last two weeks there was rapid deterioration with severe general weakness, spreading ulceration and gangrene in the hands and feet, rapid development of decubitus ulcers, and, finally, bronchopneumonia.

The only form of therapy worth comment was A.C.T.H. given for 31 days $(50 \mathrm{mg}$. six-hourly for three days, $50 \mathrm{mg}$. twice daily for 10 days, $25 \mathrm{mg}$. twice daily for 18 days intramuscularly). This made the patient euphoric and produced considerable relief from pain, but it could not be said to have affected in any way the progress of the disease.

Post-MORTEM Findings.-The body was that of a very emaciated woman (weight $37 \mathrm{~kg}$.). On the external surface of the body there were no features to add to those already described. A mucoid exudate was found on the surface of the pericardium, peritoneum, and pleura.

The heart was enlarged, weighing $390 \mathrm{~g}$. Both left and right ventricles were hypertrophied, the left measuring $17 \mathrm{~mm}$. and the right $7 \mathrm{~mm}$. The endocardium was normal in the ventricles, but thickened in the auricles. The myocardium was normal on section. The mitral valve was thickened, calcified, and stenosed, just admitting one finger (Fig. 2). The chordae tendineae were shortened and fibrosed. The other valves were normal. The coronary arteries and aorta showed slight atheroma.

The right pleura contained about 2 pints of clear straw-coloured fluid. The lungs were fibrotic and cystic. The peripheral part of the left upper lobe was fibrotic. At the apex of this lobe the fibrosis extended to a depth of $1 \mathrm{~cm}$., but at the base to a depth of $4 \mathrm{~cm}$. In the fibrosed area there were occasional groups of cysts, up to a dozen, just visible to the naked eye. The whole of the left lower lobe was fibrosed, nearly the whole of the lower half being replaced by cysts up to $0.5 \mathrm{~cm}$. in diameter (Fig. 3). In the upper half of the left lower lobe, the cysts, although numerous, were just visible to the naked eye and were situated in a band $1 \mathrm{~cm}$. deep below the pleura, with an occasional group deeper. The distribution of the cysts in the right lung was similar to that in the left, with the addition that the middle lobe was fibrosed throughout, and the outer half was replaced entirely by small cysts. The branches of the pulmonary artery were markedly atheromatous.

The oesophagus was dilated in its lower third, but was not ulcerated, scarred, thickened, or rigid. The rest of the gastro-intestinal tract was normal. The liver and spleen were in a state of advanced chronic venous congestion. All other organs were normal.

Microscopy.-The skin from the thorax, abdomen, cubital fossa, and foot showed flattening of the epidermis and dense collagen formation in the corium, with fragmentation and splitting of the fibres. The intima of some of the vessels was thickened and around the vessels collections of chronic inflammatory cells, mainly lymphocytes, were occasionally observed. Sebaceous and sweat glands were still present although surrounded by dense collagen; a 


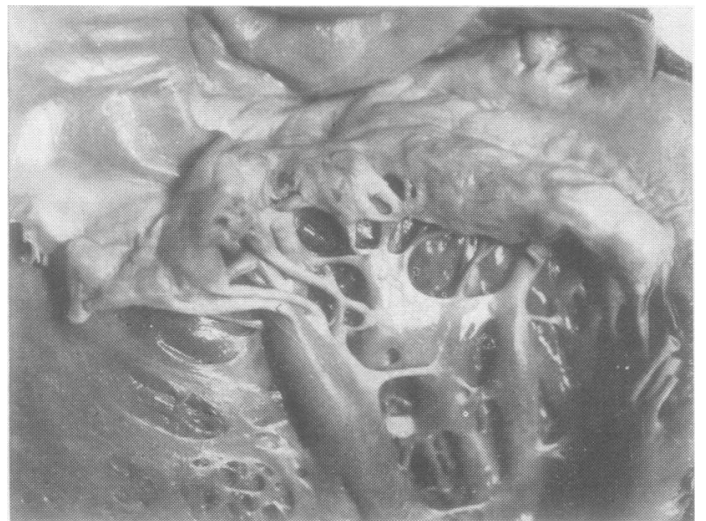

FIG. 2.

Fig. 1.-Radiograph taken eight weeks before death showing linear shadowing and cystic pattern, more pronounced on the right and in the lower zones, enlargement of the cardiac outline, and some prominence of the pulmonary artery.

Fig. 2.-The stenotic mitral valve, natural size.

FIG. 3.-A large section of part of the lower lobe of the left lung stained by the method of Gough and Wentworth (1949) showing cystic changes. One and half times natural size.

FIG. 4.-Photomicrograph of lung in which it is seen that the normal lung is replaced by many cysts, mostly lined with epit helium. $\times 11$.

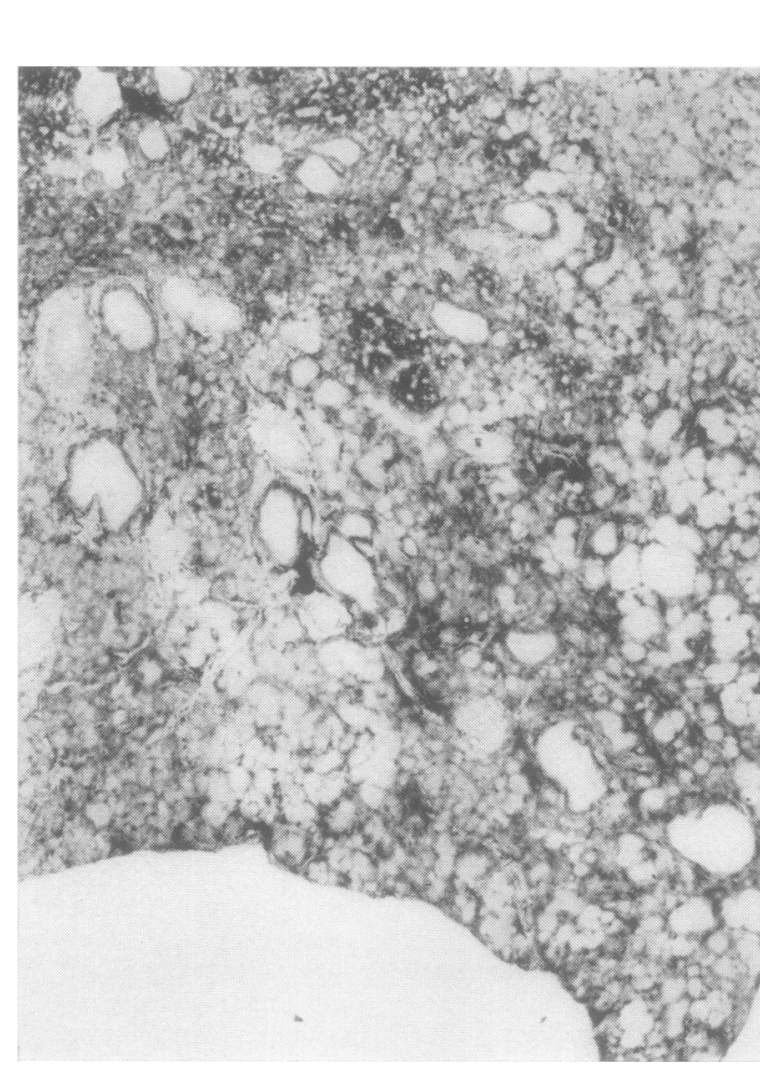

FIG. 3.

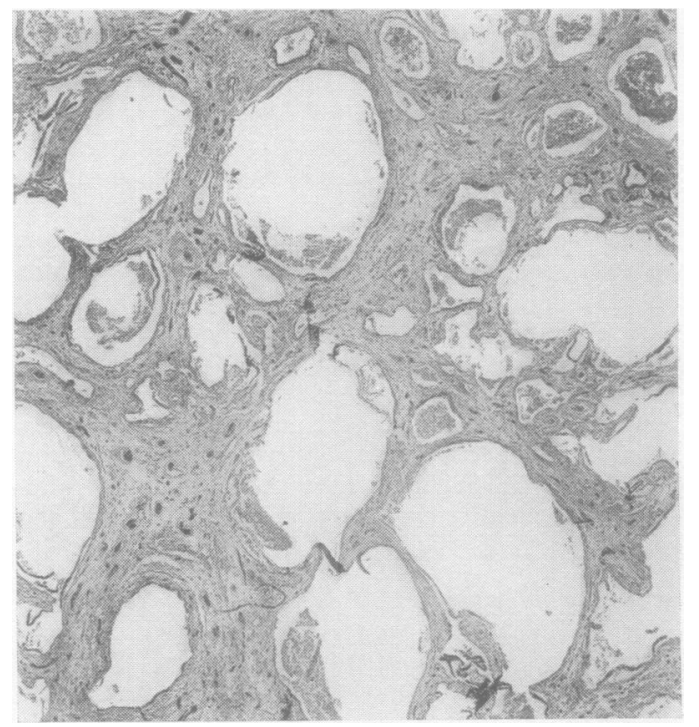

Fig. 4. 
few of the sweat glands were atrophic. Six pieces of skeletal muscle were taken, but only one was abnormal. It showed obliterative changes in the small blood vessels and degenerating muscle fibres, some of which were deeply basophilic.

The muscle fibres of the oesophagus were interspersed with collagen, and an increased amount of collagen was found in the submucous layer. Numerous sections taken throughout the rest of the gut revealed no abnormality.

The cysts in the lungs (Fig. 4) were mostly lined with ciliated columnar epithelium, sometimes the cilia were absent, more rarely the epithelium was cuboidal, flattened, or absent. In the walls of the cysts (Fig. 5) strands of muscle fibres were prominent,

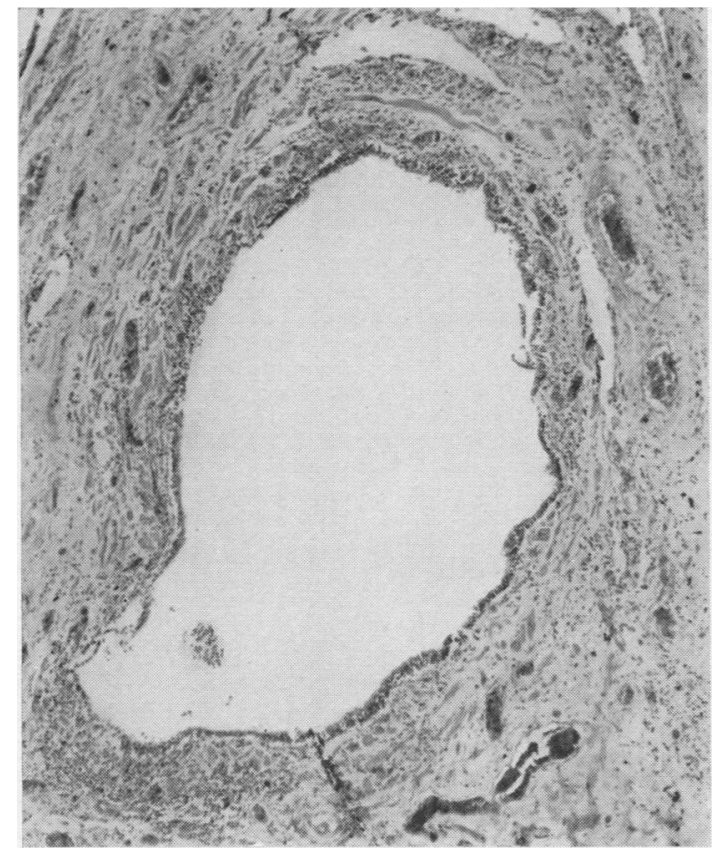

FIG. 5.-Photomicrograph of a single cyst lined with ciliated columnar epithelium surrounded by vascular fibrous tissue and strands of muscle. $\times 25$.

but there was no increase of elastic fibres. Surrounding the cysts vascularized fibrous tissue with collections of chronic inflammatory cells were to be found. Areas which appeared to the naked eye to be fibrotic were shown microscopically to contain numerous minute cysts. In the remaining areas of the lung, which appeared normal to the naked eye, many of the alveolar walls were thickened and alveolar cell metaplasia had occurred. Bronchopneumonia was found in the lower lobes. No Aschoff nodules were seen in the myocardium, but a few widely scattered very small areas of fibrosis were present. The liver and spleen showed the changes of chronic venous congestion. The kidneys, gall-bladder, thyroid, pituitary, adrenals, pancreas, bladder, tonsils, uterus, and ovaries were normal.

\section{Discussion}

Although the presence of diffuse pulmonary fibrosis is now fairly well known in scleroderma, the present case is remarkable pathologically for the numerous cysts in the fibrotic areas of the lungs. Some of these cysts had no epithelium, but the majority were lined with epithelium, for the most part ciliated, but sometimes cubical or flattened. Muscle and fibrous tissue were prominent features of the cyst walls. Elastic tissue hyperplasia was reported by Aronson and Wallerstein (1950), but we did not find it, nor did Getzowa (1945). Getzowa (1945), Spain and Thomas (1950), and Aronson and Wallerstein (1950) describe hyalinization and breakdown of the alveolar walls, but this feature was not present in our case. Getzowa suggests that, following the disappearance of the alveolar walls, bronchiolar proliferation occurs to form outgrowths from which cysts develop. Spain and Thomas (1950) consider that the cysts arise for the most part as a consequence of dissolution of tissue, but they also think that some cysts are produced in the same way as the bullae of obstructive emphysema. The presence of muscle in the cyst walls in our case indicates that the cysts are bronchiolar in origin. The cystic dilatation of the bronchioles may well be caused by contraction of the fibrous tissue in the lung parenchyma. The pulmonary fibrosis could be the end-result of a similar process to that causing scleroderma, but it may be post-inflammatory in nature in view of the many chronic inflammatory cells and the history of lung infection. It is possible that the induration of the pharynx, and the disordered function of the oesophagus, may have resulted in a prolonged series of aspirations extending over many years, giving rise to pulmonary fibrosis as described by Belcher (1949). The cystic changes in the lungs of scleroderma resemble those of honeycomb lung as described by Oswald and Parkinson (1949). Scleroderma can be included amongst the group of conditions in which honeycomb lung may occur.

An attempt was made to see if the areas of fibrosis in the myocardium satisfied the criteria laid down by Weiss, Stead, Warren, and Bailey (1943) and Goetz (1945) for sclerodermatous heart disease, but no satisfactory conclusion could be reached because of the presence in our case of coronary artery disease. The changes found in the mitral valve are typical of rheumatic mitral stenosis. Acute rheumatism and scleroderma were claimed by Crocker (1880) to be frequently associated, and many early authors suggested a possible aetiological relationship. Hebra and Kaposi 
(1874) thought that rheumatic pains and even frank arthritis had frequently been present in patients who later developed scleroderma. They could not, however, attribute any aetiological significance to these observations. Castle (1923) dismissed the hypothesis that there was any association between acute rheumatism and scleroderma, on the grounds that heart disease of any kind was rare in scleroderma. MacCallum (1926) claimed that his case with acute and subacute rheumatism had also acute scleroderma, but none of the histological features of scleroderma were found at necropsy. Klingman (1930) described a number of cases in which scleroderma or dermatomyositis was associated with rheumatic fever, or with rheumatic heart disease, but we are not convinced that he has shown this relationship in any of his cases with generalized scleroderma.

Although recently both rheumatic fever and scleroderma have been attributed to a disorder of collagen, we can find little support in the literature for the clinical association between them. The rarity of mitral stenosis (the commonest rheumatic valvular lesion) in patients with scleroderma supports our belief that the relationship, when it occurs, can be attributed to chance.

\section{SUMMARY}

A case of scleroderma (acrosclerotic type) with honeycomb lung and mitral stenosis is described.
The cysts in the lung are thought to be caused $\stackrel{\overrightarrow{\bar{F}}}{+}$ by contraction of the fibrous tissue of the lung? parenchyma.

The fibrous tissue may be the end-result of as sclerodermatous or chronic inflammatory process. $\varrho$

The finding of mitral stenosis in a case of scleroderma is probably fortuitous.

We thank Professors J. Gough and H. Scarborough $\overrightarrow{-}$ for their criticism and advice, Mr. J. E. Wentworth for the preparation of the large lung section, Mr. J. P. Napper and Mr. R. J. Marshall for the photographs.

\section{REFERENCES}

Aronson, S. M., and Wallerstein, L. (1950). N.Y. St. J. Med., 50, 2723. Belcher, J. R. (1949). Thorax, 4, 44.

Castle, W. F. (1923). Brit. J. Derm., 35, 255 and 303

Church, R. E., and Ellis, A. R. P. (1950). Lancet, 1, 392.

Crocker, H. R. (1880). Trans. path. Soc. Lond., 31, 315. - (1885). Lancet, 1, 237.

Dostrovsky, A. (1947). Arch. Derm. Syph., Chicago, 55, 1.

Getzowa, S. (1945). Arch. Path., Chicago, 40, 99.

Goetz, R. H. (1945). Clin. Proc., 4, 337.

Gough, J., and Wentworth, J. E. (1949). Proc. 9th Internat. Cong. I Industr. Med. London., 1948, p. 661. Wright, Bristol.

Hayman, L. D., and Hunt, R. E. (1952). Dis. Chest, 21, 691.

Hebra, F., and Kaposi, M. (1874). On Diseases of the Skin, vol. 3, O New Sydenham Society, London.

Klingman, W. O. (1930). Arch. Neurol. Psychiat., Chicago, 24, 1187.

MacCallum, W. G. (1926). Trans. Ass. Amer. Phys., 41, 190.

Oswald, N., and Parkinson, T. (1949). Quart. J. Med., 18, 1.

Rake, G. (1931). Bull. Johns Hopk. Hosp, 48, 212.

Ramond, L. (1928). Cited by Basch, M. (1932). Le Syndrome de $\overrightarrow{\vec{D}}$ Thibierge-Weissenbach. Thèse de Paris.

Ramsey, A. S. (1951). Brit. med. J., 2, 877.

Spain, D. M., and Thomas, A. G. (1950). Ann. intern. Med., 32, $152 . \supset$

Weiss, S., Stead, E. A., Warren, J. V., and Bailey, O. T. (1943). Arch. intern. Med., 71, 749. 